\title{
Algoritmo de Gower na estimativa da divergência genética em germoplasma de pimenta
}

\author{
Maria da Cruz CL Moura ${ }^{1}$; Leandro SA Gonçalves²; Cláudia P Sudré; Rosana Rodrigues²; Antonio T do \\ Amaral Júnior²; Telma NS Pereira² \\ 'UFMA-CCAA, Campus IV, Centro, 65000-000 Chapadinha-MA; ${ }^{2}$ UENF-LMGV, Av. Alberto Lamego, 2000, Pq. Califórnia, 28013-602 \\ Campos dos Goytacazes-RJ; lsagrural@yahoo.com.br; rosana@uenf.br
}

\section{RESUMO}

A estimativa da variabilidade genética existente em um banco de germoplasma é importante não só para a conservação dos recursos genéticos, mas também para sua utilização no melhoramento de plantas. Os acessos de um banco são estudados com base em descritores quantitativos e qualitativos. Porém, nem sempre esses dados são analisados simultaneamente. O presente trabalho teve como objetivo estudar a divergência genética entre 56 acessos de Capsicum chinense procedentes da Coleção de Germoplasma da Universidade Estadual do Norte Fluminense Darcy Ribeiro, com base em 44 descritores morfoagronômicos, 37 qualitativos e sete quantitativos, utilizando-se a análise conjunta baseada no algoritmo de Gower. Utilizou-se o delineamento inteiramente ao acaso, com três repetições e três plantas por parcela. As plantas estudadas cresceram em vasos de $5 \mathrm{~L}$. Houve variabilidade fenotípica entre os acessos de pimenta estudados, principalmente nos frutos, que mostraram diferenças acentuadas em tamanho, formato, coloração, teores de sólidos solúveis totais e vitamina $\mathrm{C}$. O método aglomerativo utilizado foi UPGMA por ter maior coeficiente de correlação cofenética $(r=0,82)$. Os acessos estudados dividiram-se em seis grupos. O agrupamento com base na distância de Gower revelou maior eficiência na disjunção dos genótipos quando foram utilizadas as variáveis qualitativas em comparação às quantitativas, indicando uma maior contribuição daquelas na explicação dos agrupamentos. A análise conjunta dos dados quantitativos e qualitativos resultou em maior eficiência na determinação da divergência genética entre os acessos avaliados, sendo uma alternativa viável e uma ferramenta importante para o conhecimento da variabilidade em bancos de germoplasma.

Palavras-chave: Capsicum chinense, análise multivariada, germoplasma, recursos genéticos vegetais.

\section{ABSTRACT}

The Grower's algorithm on the estimate of genetic diversity in chili pepper germoplasm

The estimation of genetic variability in germplasm collections is important not only for the conservation of genetic resources, but also for plant breeding purposes. Accessions in a germplasm bank are studied based on quantitative and qualitative descriptors. However, these data are rarely considered simultaneously in joint analyses. This work aimed to study the genetic diversity among 56 Capsicum chinense accessions coming from the Germplasm Collection of the Universidade Estadual do Norte Fluminense Darcy Ribeiro (UENF). We used 44 morpho-agronomic descriptors, 37 qualitative and seven quantitative, and the Grower's algorithm for the joint analysis. We used a completely randomized design with three replications and three-plant plots. Plants grew in $5 \mathrm{~L}$ pots. There was phenotypic variability among the chili accessions studied, mainly in fruits. Marked differences were observed in size, shape, color and total soluble solids and vitamin C contents of fruits. We used UPGMA to perform the clustering, since it was the method with the higher cophenetic correlation coefficient $(\mathrm{r}=0.82)$. Accessions felt into six classes. Gower's algorithm was more efficient in clustering when qualitative instead of quantitative data were considered. It indicates that qualitative data played a crucial role in explaining the observed groupings. Joint analysis of quantitative and qualitative data resulted in greater efficiency in the determination of genetic divergence among the accessions evaluated. Therefore, such analysis is definitely a viable and important tool for understanding the variability within germplasm banks.

Keywords: Capsicum chinense, multivariate analysis, germplasm, plant genetic resources.

(Recebido para publicação em 6 de janeiro de 2009; aceito em 31 de março de 2010)

(Received on January 6, 2009; accepted on March 31, 2010)

$\mathrm{O}$ mercado de pimentas no Brasil, considerado até pouco tempo secundário em relação às outras hortaliças devido ao baixo consumo e ao pequeno volume comercializado, vem sofrendo fortes transformações e assumindo grande importância para o País, devido principalmente à versatilidade de aplicação das pimentas no uso culinário, industrial, medicinal e ornamental (Moreira et al., 2006). Outro fato que se deve salientar é a importância sócioeconômica, pois o cultivo de pimentas contribui para o aumento da renda nas pequenas propriedades e para a fixação de trabalhadores na área rural, já que são grandes demandantes de mão-de-obra para a colheita (Sudré et al., 2010).

As pimentas estão incluídas no gênero Capsicum, em 31 espécies descritas, divididas em domesticadas, semidomesticadas e silvestres (Pozzobon et al., 2006; Moscone et al., 2007). Entre as espécies domesticadas, $C$. chinense é considerada a mais brasileira, por ter como centro de diversidade a região da Bacia Amazônica (Bosland, 1992). Esta espécie destaca-se pela sua ampla adap- tação às condições de clima equatorial e tropical e por possuir grande variabilidade genética, evidenciada principalmente nos frutos que podem ter diferentes formatos, colorações, tamanhos e níveis de pungência, sendo uma das espécies de pimenta mais produzidas e consumidas no Brasil (Carvalho et al., 2003; Lannes et al., 2007).

A manutenção e conservação desta variabilidade em bancos de germoplasma é de fundamental importância para o melhoramento genético e para a segurança em relação às ameaças impre- 
vistas na produção agrícola, tais como epifitias e mudanças climáticas (Gepts, 2006). Entretanto, essas coleções de germoplasma devem ser caracterizadas e avaliadas com o objetivo de determinar a diversidade genética, permitir a identificação de acessos úteis em programas de melhoramento de plantas e para detecção de duplicatas (Franco et al., 2005; Gepts, 2006; Sudré et al., 2007a; Sudré et al., 2010).

A determinação da diversidade genética é realizada por meio da variação entre indivíduos ou grupos dos indivíduos ou entre populações, podendo ser analisada por um método específico ou por uma combinação de métodos. Os dados envolvem frequentemente medidas numéricas e distribuição em classes e, em muitos casos, combinações de variáveis de tipos diferentes (Mohammadi \& Prasanna, 2003), por exemplo variáveis quantitativas (altura da planta, peso do fruto, dias para o florescimento) e qualitativas (cor e formato de fruto, presença ou ausência de uma característica, marcador molecular) (Franco et al., 2001; Gonçalves et al., 2009; Barbé et al., 2010). Embora a análise conjunta das variáveis quantitativas e qualitativas seja potencialmente um indicador mais completo da variabilidade existente nos bancos de germoplasma, poucos trabalhos têm utilizado esta estratégia. Provavelmente, isso ocorre devido à falta de conhecimento das técnicas estatísticas que permitem essa abordagem, à carência de softwares livres que analisem esses dados conjuntamente, bem como pela tendência dos pesquisadores em dar mais importância àquelas variáveis diretamente relacionadas com caracteres trabalhados em programas de melhoramento (Gonçalves et al., 2008).

Uma técnica que permite a análise simultânea de dados quantitativos e qualitativos foi proposta por Gower (1971), por meio de um algoritmo que estima a similaridade entre dois indivíduos utilizando dados com distribuições contínuas e discretas. Esse tipo de análise tem sido muito utilizado em estudos relacionados à botânica e taxonomia, entretanto, ainda não tem sido bem explorado pelos pesquisadores na área de recursos genéticos vegetais para detecção da variabilidade em coleções de germoplasma. Trabalhos recentes descrevem o uso desta estratégia em Brassica napus L. (Rodríguez et al., 2005), Triticum aestivum L. (Vieira et al., 2007) e Solanum lycopersicum (Gonçalves et al., 2008).

Este trabalho teve como objetivo estimar a divergência genética entre 56 acessos de pimenta utilizando o algoritmo de Gower para o estudo conjunto de dados quantitativos e qualitativos.

\section{MATERIAL E MÉTODOS}

Foram estudados 56 acessos de $C$. chinense da coleção de germoplasma do Centro de Ciências e Tecnologias Agropecuárias (CCTA) da Universidade Estadual do Norte Fluminense Darcy Ribeiro (UENF) (Tabela 1). O experimento foi conduzido em casa de vegetação, no município de Campos dos Goytacazes, RJ, no período de março a dezembro de 2006. A semeadura foi realizada em bandejas de poliestireno expandido de 128 células preenchidas com substrato orgânico. As mudas foram transplantadas 45 dias após a semeadura para vasos plásticos de $5 \mathrm{~L}$, contendo uma mistura de solo e esterco na proporção de 3:1. Utilizou-se o delineamento inteiramente ao acaso, com três repetições e três plantas por parcela.

Na caracterização morfoagronômica dos acessos foram utilizados 43 descritores, estabelecidos pelo IPGRI (1995), com algumas alterações sugeridas por Carvalho et al. (2003), 37 qualitativos e sete quantitativos. Os descritores qualitativos foram: cor, formato e pubescência da haste; antocianina nodal; hábito de crescimento; densidade da ramificação; brotação abaixo da primeira bifurcação; densidade, cor, forma e pubescência da folha; dias para o início do florescimento; número de flores/ axila; posição da flor; cor da corola e da mancha da corola; forma da corola; cor da antera e do filamento; posição do estigma; margem do cálice; dias para o início da frutificação; cor do fruto imaturo e maduro; posição, formato, ombro, superfície e aroma do fruto; constrição anelar no cálice; formato da posição do fruto; seção transversal; número de lóculos; persistência entre fruto/pedicelo; comprimento da placenta; pungência, de acordo com a coloração da placenta, conforme proposto por Derera (2000) e; cor da semente. Em relação aos descritores quantitativos, foram utilizados: comprimento $(\mathrm{mm})$, largura $(\mathrm{mm})$ e peso do fruto $(\mathrm{g})$; comprimento do pedúnculo ( $\mathrm{mm})$; espessura da parede do fruto $(\mathrm{mm})$; teor de sólidos solúveis ( ${ }^{\circ}$ Brix) e teor de vitamina C (mg $100 \mathrm{~g}^{-1}$ polpa). Os teores de vitamina $\mathrm{C}$ foram determinados utilizando-se o método oficial AOAC (1984). Para os descritores quantitativos foram analisados dez frutos de cada acesso.

A estimação da matriz de distância genética foi realizada por meio da análise conjunta das variáveis quantitativas e qualitativas obtidas com base no algoritmo de Gower (1971), expresso por:

$$
S_{i j k}=\frac{\sum_{k=1}^{p} W_{i j k} \cdot S_{i j k}}{\sum_{K=1}^{p} W_{i j k}} \text {, onde: }
$$

$\boldsymbol{K}=$ o número de variáveis $(\mathrm{k}=1$, $2, \ldots, p) ; \mathbf{i}$ e $\mathbf{j}=$ dois indivíduos que representem o acesso; $\boldsymbol{W}_{i j k}=$ peso dado à comparação ijk, atribuindo valor $\mathbf{1}$ para comparações válidas e valor $\mathbf{0}$ para comparações inválidas (quando o valor da variável está ausente em um ou ambos indivíduos); $\boldsymbol{S}_{i j k}=$ contribuição da variável $\mathbf{k}$ na similaridade entre os indivíduos i e j, com valores entre $\mathbf{0}$ e $\mathbf{1}$. Para uma variável qualitativa (nominal), se o valor da variável $\mathbf{k}$ é o mesmo para ambos os indivíduos, $\mathbf{i}$ e $\mathbf{j}$, então $\mathbf{S}_{\mathbf{i j k}}=$ $\mathbf{1}$, caso contrário, é igual a $\mathbf{0}$; para uma variável quantitativa (contínua) $\mathbf{S}_{\mathrm{ijk}}=$ $1-\left|\mathbf{x}_{\mathrm{ik}}-\mathbf{x j k}\right| / \mathbf{R}_{\mathrm{k}}$ onde $\mathbf{x}_{\mathrm{ik}}$ e $\mathbf{x}_{\mathrm{jk}}$ são os valores da variável $\mathbf{k}$ para os indivíduos i e j, respectivamente, e $\mathbf{R}_{\mathbf{k}}$ é o intervalo (valor máximo menos valor mínimo), da variável $\mathbf{k}$ na amostra. A divisão por $\mathbf{R}_{\mathbf{k}}$ elimina as diferenças entre escalas das variáveis, produzindo um valor dentro do intervalo $[\mathbf{0}, \mathbf{1}]$ e pesos iguais.

Os agrupamentos dos acessos foram obtidos pelos métodos de UPGMA (Unweighted Pair-Group Method Using an Arithmetic Average), Ward e Vizinho Mais Próximo (VMP). A validação dos agrupamentos foi determinada pelo coeficiente de correlação cofenético (CCC) (Sokal \& Rolf, 1962). Os dados foram analisados pelo programa R (http:// 
www.r-project.org/), utilizando o pacote clusters e o procedimento proposto por Daisy (Maechler, 2007).

\section{RESULTADOS E DISCUSSÃO}

Detectou-se variabilidade fenotípica entre os acessos de pimenta estudados com base nos descritores morfoagronômicos, principalmente nos frutos para os quais foram registradas diferenças visuais acentuadas em termos de tamanho, formato, coloração, teores de sólidos solúveis totais e de vitamina C. O tamanho dos frutos variou de 12,9 a 124 $\mathrm{mm}$, tendo sido o formato campanulado predominante em 41,0\% dos acessos, seguido pelos formatos alongado, retangular, triangular e arredondado, em 23,2, 21,4, 8, 1 e 6,3\%, respectivamente. Houve maior ocorrência de acessos de frutos vermelhos, seguidos de frutos amarelos, laranja e marrom, com 60,7, 30,4, 5,4 e 3,5\%, respectivamente.

Em relação ao teor de sólidos solúveis totais, registraram-se frutos com valores de $5,1^{\circ}$ Brix (UENF 1763) a 15,4 ${ }^{\circ}$ Brix (UENF 1753). Também houve ampla variabilidade no teor de vitamina $C$, que foi de $65 \mathrm{mg} 100 \mathrm{~g}^{-1}$ (acesso UENF 1709) a 262,0 mg $100 \mathrm{~g}^{-1}$ (acesso UENF 1768). Registros mais baixos para teores de vitamina $\mathrm{C}$ foram encontrados por Lannes (2005) que trabalhou com 40 acessos de $C$. chinense do banco de germoplasma da Universidade Federal de Viçosa e obteve variação de vitamina C entre 38,7 e 138,8 mg $100 \mathrm{~g}^{-1}$. Esses valores discrepantes podem ser devidos principalmente à metodologia de extração da vitamina $\mathrm{C}$, já que Lannes (2005) utilizou o método titulométrico de Tillmans, descrito pelo Instituto Adolfo Lutz (1985), enquanto neste trabalho utilizou-se o método AOAC (1984). Outra possibilidade para essa discrepância é a variabilidade genotípica que pode existir entre os diferentes acessos, já que este é um caráter controlado geneticamente. Além desses fatores, as condições de cultivo também podem ter interferido no teor da vitamina $\mathrm{C}$.

Uma análise conjunta dos descritores vitamina $\mathrm{C}$ e cor do fruto maduro neste trabalho permitiu observar uma amplitude de variação de 65 a 262 mg $100 \mathrm{~g}^{-1}$ no teor de vitamina C para frutos vermelhos, que foram predominantes entre os acessos (Figura 1A). Por sua vez, a análise conjunta do teor de vitamina $\mathrm{C}$ e da pungência também evidenciou alta variabilidade para teor de vitamina $\mathrm{C}$ nos frutos considerados doces, que apresentaram os maiores teores de vitamina $\mathrm{C}$ (Figura 1B). Neste caso, os teores de vitamina $\mathrm{C}$ variaram entre 73 e $262 \mathrm{mg} 100 \mathrm{~g}^{-1}$. Este resultado contradiz Bosland \& Votava (2000), que afirmaram que frutos doces de pimenta possuem menor concentração de vitamina $\mathrm{C}$ que frutos de alta pungência. Todos os frutos doces apresentavam coloração vermelha ou marrom. Ao contrário, pungência foi observada em frutos de todas as cores (Figura 1C).

Os acessos não diferiram para os descritores cor da semente, da corola e da mancha da corola e constrição anelar no cálice. Este resultado era esperado já que estes descritores são considerados os principais para identificação da espécie $C$. chinense na classificação taxonômica. O descritor constrição anelar no cálice, localizado entre o cálice e o pedúnculo, é considerado a principal característica morfológica para distinção entre as espécies $C$. chinense e $C$. frutescens, que apresentam muita semelhança (Carvalho et al., 2003).

Tabela 1. Identificação e procedência de 56 acessos de Capsicum chinense do banco de germoplasma da UENF, caracterizados e avaliados para 44 descritores quantitativos e qualitativos (identification and origin of 56 Capsicum chinense accessions from the germplasm bank of the UENF characterized and evaluated for 44 quantitative and qualitative descriptors). Campos dos Goytacazes, UENF, 2006.

\begin{tabular}{|c|c|c|c|}
\hline Acesso & Procedência & Acesso & Procedência \\
\hline UENF 1703 & Viçosa-MG & UENF 1759 & Belém-PA \\
\hline UENF 1706 & Viçosa-MG & UENF 1760 & Belém-PA \\
\hline UENF 1708 & São Luís-MA & UENF 1762 & Belém-PA \\
\hline UENF 1709 & São Luís-MA & UENF 1763 & Belém-PA \\
\hline UENF 1713 & São Luís-MA & UENF 1764 & Belém-PA \\
\hline UENF 1715 & Peru & UENF 1765 & Bélem-MA \\
\hline UENF 1720 & Ilhéus-BA & UENF 1767 & Bélem-MA \\
\hline UENF 1721 & Ilhéus-BA & UENF 1768 & Bélem-MA \\
\hline UENF 1722 & Ilhéus-BA & UENF 1770 & Bélem-MA \\
\hline UENF 1723 & Ilhéus-BA & UENF 1771 & Bequimão-MA \\
\hline UENF 1725 & Ilhéus-BA & UENF 1772 & Bequimão-MA \\
\hline UENF 1726 & Ilhéus-BA & UENF 1773 & Bequimão-MA \\
\hline UENF 1730 & Peru & UENF 1774 & Bequimão-MA \\
\hline UENF 1736 & São Domingos-ES & UENF 1778 & Bequimão-MA \\
\hline UENF 1739 & Itaguaí-RJ & UENF 1780 & Bequimão-MA \\
\hline UENF 1742 & Belém-PA & UENF 1781 & Bequimão-MA \\
\hline UENF 1743 & Marajó-Souré-PA & UENF 1782 & Bequimão-MA \\
\hline UENF 1745 & Marajó-Souré-PA & UENF 1784 & São Luís-MA \\
\hline UENF 1746 & Marajó-Souré-PA & UENF 1785 & São Luís-MA \\
\hline UENF 1748 & Marajó-Souré-PA & UENF 1786 & São Luís-MA \\
\hline UENF 1749 & Desconhecida & UENF 1787 & São Luís-MA \\
\hline UENF 1751 & Parintins-AM & UENF 1788 & São Luís-MA \\
\hline UENF 1752 & Ilhéus-BA & UENF 1789 & São Luís-MA \\
\hline UENF 1753 & Ilhéus-BA & UENF 1791 & São Luís-MA \\
\hline UENF 1755 & Peru & UENF 1792 & São Luís-MA \\
\hline UENF 1756 & Ilhéus-BA & UENF 1793 & São Luís-MA \\
\hline UENF 1757 & Ilhéus-BA & UENF 1794 & São Luís-MA \\
\hline UENF 1758 & Ilhéus-BA & UENF 1798 & Campos-RJ \\
\hline
\end{tabular}




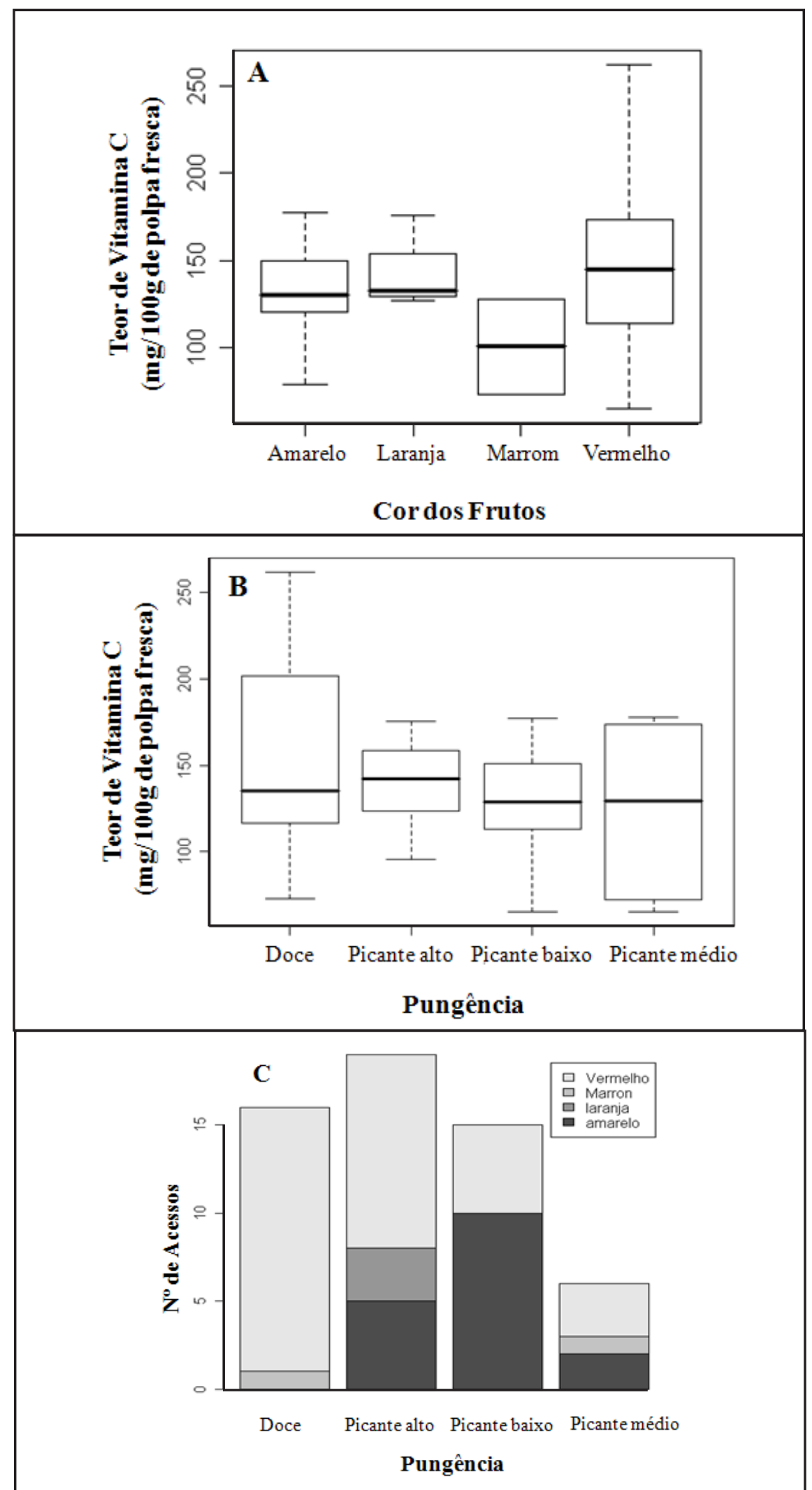

Figura 1. A. Boxplot dos valores mínimos, máximos e a mediana $(25,50$ e 75$)$ do teor de vitamina $\mathrm{C}$ em relação à coloração dos frutos. B. Boxplot dos valores mínimos, máximos e a mediana $(25,50$ e 75$)$ do teor de vitamina $C$ em relação à pungência. $C$. Histograma associando a cor do fruto à pungência (A. Boxplot of minimum, maximum and median values $(25,50$ and 75$)$ of vitamin $\mathrm{C}$ related to fruit color. B. Boxplot of minimum, maximum and median values $(25,50$ and 75$)$ of vitamin $C$ related to pungency. C. Histogram associating fruit color to pungency). Campos dos Goytacazes, UENF, 2006.
Os acessos incluídos neste estudo já haviam sido avaliados quanto à resistência a dois patógenos de grande importância para a cultura da pimenta: a mancha-bacteriana (Xanthomonas campestris pv. vesicatoria, Xcv) e o PepYMV (Pepper Yellow Mosaic Virus). Dois acessos (UENF 1759 e UENF 1785) tiveram reação de hipersensibilidade à raça $\mathrm{P} 3$ de Xcv (Sudré et al., 2007b), enquanto os acessos UENF 1703, UENF 1730, UENF 1751, UENF 1755 e UENF 1764 foram resistentes ao PepYMV (Bento et al., 2009).

Utilizando-se o algoritmo de Gower para análise conjunta de todos os descritores morfoagronômicos, identificou-se que os acessos UENF 1709 e UENF 1791 foram os mais distantes, com magnitude 0,62, enquanto UENF 1787 e UENF 1798 foram os mais similares, com valor de 0,17 . A distância média observada entre os acessos foi 0,40 $( \pm 0,08)$. Interessante observar que os acessos mais distantes tiveram a mesma procedência (São Luís, MA) enquanto os mais similares provieram de diferentes locais: UENF 1787, de São Luís, e UENF 1798, de Campos dos Goytacazes, RJ. Este resultado coincide com outros encontrados na literatura para Cucurbita moschata e Brassica napus que indicam que distâncias geográficas não se correlacionam com distâncias genéticas entre acessos (Ramos, 2003, Rodríguez et al., 2005). No caso das pimentas, que possuem uma eficiente e rápida disseminação não só por meio de pássaros (Bosland, 1992), mas também pela ação do homem que troca sementes e as transporta livremente entre as diferentes regiões, essa ausência de relação entre procedência e divergência é ainda mais justificada.

O agrupamento hierárquico UPGMA foi mais fidedigno do que os agrupamentos Ward e VMP, uma vez que, comparativamente as inferências da correlação cofenética foram superiores, obtendo-se valores de 0,82, 0,59 e 0,62 para UPGMA, Ward e VMP, respectivamente. Na concepção de Sokal \& Rohlf (1962), valores de correlação cofenética superiores a 0,80 indicam bom ajuste entre as matrizes originais de distância e as derivadas das distâncias gráficas, o que ratifica a maior confiabilidade do 


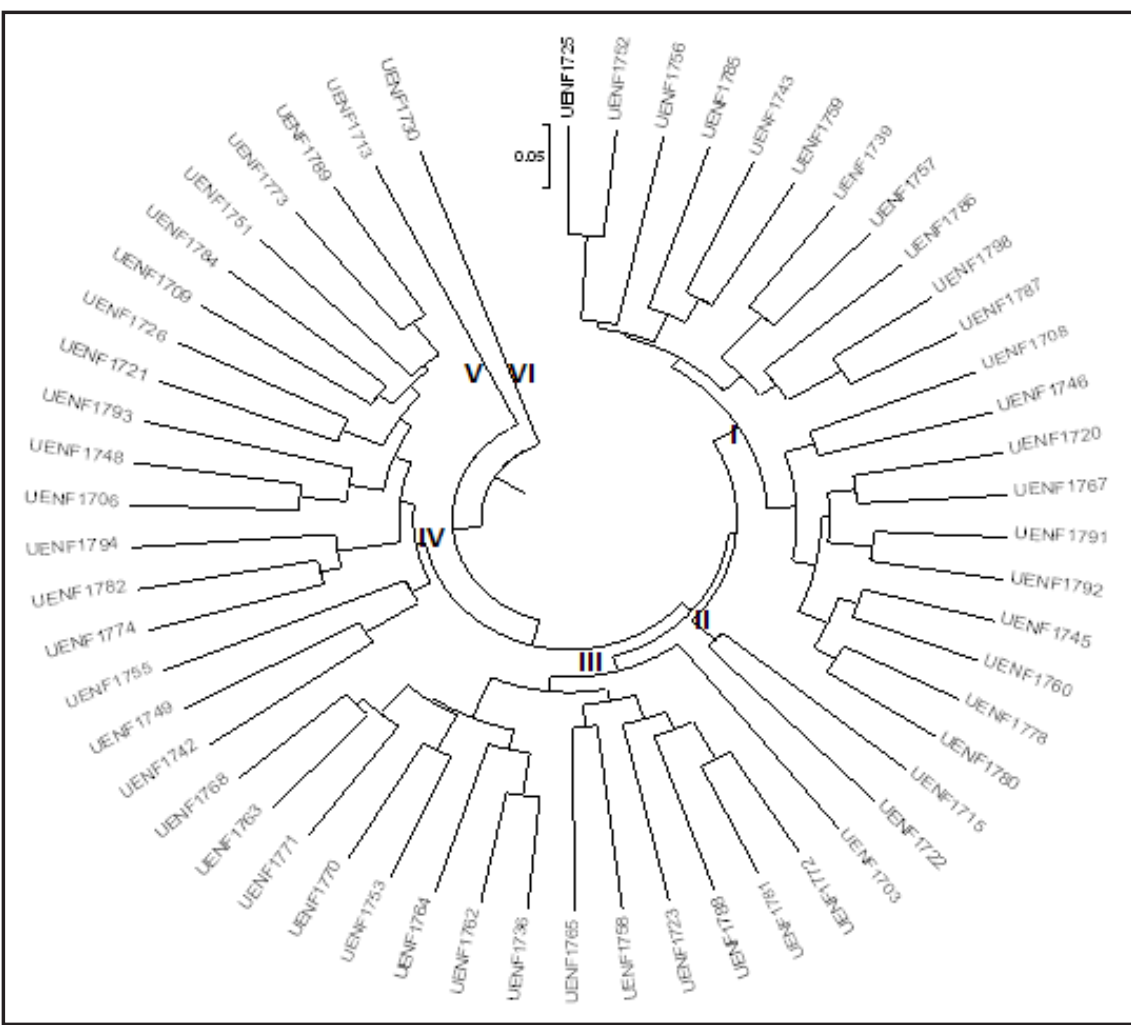

Figura 2. Dendrograma UPGMA de 56 acessos de Capsicum chinense utilizando-se a distância de Gower para as variáveis conjuntas (qualitativa + quantitativa) (UPGMA dendrogram of 56 Capsicum chinense accessions based on Gower distance for quantitative and qualitative variables). Campos dos Goytacazes, UENF, 2006.

agrupamento do método UPGMA.

Utilizando-se o agrupamento UPGMA com um ponto de corte correspondendo a uma mudança abrupta no gráfico, formaram-se seis grupos (Figura 2). O grupo I foi constituído pelo maior número de acessos, totalizando 21 genótipos. Este grupo possui predominantemente plantas de hábito de crescimento intermediário, com densidade de ramificação esparsa e tipo de folha ovalada. Os frutos desse grupo possuem coloração amarela, vermelho e laranja, com formatos arredondados, triangulares, campanulados e retangulares, e com pungência variando de ausente (doce) a muito picante. Nas características quantitativas, nesse grupo observou-se ampla variabilidade no peso do fruto (variando de 0,53 a $13,27 \mathrm{~g}$ ). O teor de vitamina $\mathrm{C}$ variou de 72 a $177,57 \mathrm{mg} 100 \mathrm{~g}^{-1} \mathrm{e}$, o teor de sólidos solúveis totais, de 5,5 a $12,4{ }^{\circ}$ Brix.

O grupo II foi formado pelos acessos UENF 1715 e UENF 1722, que possuem plantas de hábito de crescimento ereto,
UENF 1768 (de Belém, PA) e UENF 1753 (de Ilhéus, BA), com valores res-

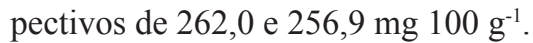

$\mathrm{O}$ grupo IV formado por 16 acessos inclui plantas com hábito de crescimento ereto, densidade de ramificação esparsa e folhas do tipo ovalada. Os frutos possuem coloração amarela, vermelha e marrom e formato alongado, e foram classificados desde doces até muito picantes, incluindo todas as categorias intermediárias. Nas características quantitativas, as plantas desse grupo possuem variabilidade no comprimento (variando de 12 a 120,6 mm) e no peso do fruto (de 0,86 a $22,22 \mathrm{~g}$ ) e nos teores de sólidos solúveis totais (de 5,7 a 13,4 ${ }^{\circ}$ Brix) e vitamina C (de 67,2 a 245,2 mg $\left.100 \mathrm{~g}^{-1}\right)$.

$\mathrm{O}$ grupo $\mathrm{V}$ foi constituído apenas pelo acesso UENF 1713 (São Luís, MA), que possui plantas de hábito de crescimento ereto, com densidade de ramificação esparsa e tipo de folha deltóide. Os frutos possuem coloração vermelha, formato campanulado e pungência média, com comprimento médio de $77,32 \mathrm{~mm}$ e peso médio de $9,73 \mathrm{~g}$. Este acesso teve o teor de sólidos solúveis totais de $6,2^{\circ}$ Brix e $65 \mathrm{mg} 100 \mathrm{~g}^{-1}$ de vitamina $C$, sendo este o menor valor entre os acessos estudados.

O grupo VI formado pelo acesso UENF 1730 (Peru) possui plantas de hábito de crescimento ereto, com ramificação densa e tipo de folha ovalada. Os frutos são de coloração marrom, formato alongado e sem pungência, com peso médio de 17,22 g. Este acesso possui comprimento do fruto de 39,35 $\mathrm{mm}$, teor de sólidos solúveis totais de $5,2^{\circ}$ Brix e teor de vitamina $\mathrm{C}$ de 73,0 $\mathrm{mg} 100 \mathrm{~g}^{-1}$.

Pôde-se observar nos grupos formados pelo agrupamento UPGMA uma maior eficiência na disjunção dos genótipos quando foram utilizadas as variáveis qualitativas em comparação às quantitativas, indicando uma maior contribuição das variáveis qualitativas na explicação dos agrupamentos formados com base nos caracteres estudados. O fato das variáveis qualitativas terem sido mais discriminantes, no entanto, não invalida a necessidade de utilizar descritores quantitativos nos estudos de divergência genética, pois estes são 
caracteres de grande relevância para programas de melhoramento. Outro aspecto a ser considerado é que a maioria das características estudadas no presente trabalho é do tipo qualitativo, no total de 37 contra apenas sete características quantitativas. Por outro lado, dentre as sete quantitativas estão as mais amplamente utilizadas na caracterização agronômica, que são peso médio, comprimento e diâmetro dos frutos. É importante salientar que cada conjunto de dados, seja morfológico, bioquímico ou molecular, ou seja, quantitativo ou qualitativo, tem suas vantagens e desvantagens para análise (Mohammadi \& Prasanna, 2003) e muitos dados têm sido gerados demonstrando a importância de se conhecer esses descritores (Costa et al., 2006; Sudré et al., 2006; Lotti et al., 2008).

Com a análise conjunta dos dados foi possível alocar os acessos em um único dendrograma utilizando-se diferentes tipos de variáveis. Isso permitiu uma melhor análise e uso dos dados qualitativos que, em geral, são analisados apenas por estatística descritiva. Em alguns casos, os dados qualitativos são transformados em multicategóricos e ficam, então, sujeitos a uma análise de agrupamento. Entretanto, ao se fazer uso desta análise, gera-se mais um dendrograma que muitas vezes não tem concordância com os agrupamentos gerados pelos dados quantitativos, causando equívocos nas interpretações e dificultando o trabalho de curadores e usuários do banco de germoplasma.

Um dos fatores considerados limitantes ao desenvolvimento e à ampla adoção de análises mistas de variáveis é a falta de softwares que ofereçam pacotes estatísticos para realização de análises com base em modelos relevantes e que, ao mesmo tempo, sejam de fácil acesso (custo baixo ou gratuito) e de fácil compreensão pelo usuário (Mohammadi \& Prasanna, 2003). O uso do programa R, um software livre e que possui vários pacotes que permitem um estudo amplo da divergência genética, facilita a realização de análises complexas e contribui para a geração de informações úteis aos curadores de bancos de germoplasma e melhoristas. O conhecimento e o uso deste programa poderão desempenhar um papel importante na área de recursos genéticos vegetais (Sudré et al., 2007a). A análise conjunta dos dados quantitativos e qualitativos permite a unificação de todas as informações em uma figura, resultando em mais eficiência na determinação da divergência genética entre os acessos de uma coleção e constituindo-se em alternativa viável e ferramenta importante para o conhecimento do germoplasma.

No caso específico de pimentas da espécie $C$. chinense, os resultados deste estudo permitiram constatar a ampla variabilidade genética existente dentro da espécie e seu potencial de uso, considerando não apenas programas de melhoramento, mas também a utilização do germoplasma per se como fonte de vitamina $\mathrm{C}$, por exemplo.

Ainda, os resultados da análise conjunta de dados obtidos no presente trabalho representam um estímulo para que os curadores de coleções de germoplasma realizem os trabalhos de caracterização de suas coleções da forma mais completa possível, pois com o uso de ferramentas estatísticas apropriadas torna-se possível a geração de informações mais seguras sobre a variabilidade e a divergência genética entre os acessos. Para os usuários desta e de outras coleções de pimenta, fica registrada a possibilidade de indicação de uso de acessos em função das características de interesse do próprio usuário.

\section{AGRADECIMENTOS}

À FAPEMA pela concessão da bolsa de pós-doutorado a primeira autora e ao Curso de Pós-Graduação em Genética e Melhoramento de Plantas da UENF, Campos dos Goytacazes, RJ, pela oportunidade de execução desta pesquisa.

\section{REFERÊNCIAS}

AOAC. (Associaton of Official Analytical Chemists). 1984. Official methods of analysis. Arlington: AOAC. 1141p.

BARBÉ TC; AMARAL JÚNIOR AT; GONÇALVES LSA; RODRIGUES R; SCAPIM CA. 2010. Association between advanced generations and genealogy in inbred lines of snap bean by the Ward-Modified Location Model. Euphytica 173: 337-343.

BENTO CS; RODRIGUES R; ZERBINI JÚNIOR
FM; SUDRÉ CP. 2009. Sources of resistance against the Pepper yellow mosaic virus in chili pepper. Horticultura Brasileira 27: 196-201.

BOSLAND PW. 1992. Chiles: a diverse crop. HortTechnology. 2: 7-10.

BOSLAND PW; VOTAVA EJ. 2000. Peppers: vegetable and spice capsicums. Wallingford: CABI. 204p.

CARVALHO SIC; BIANCHETTI LB; BUSTAMANTE PG; SILVA DB. 2003. Catálogo de germoplasma de pimentas $e$ pimentões (Capsicum spp.) da Embrapa Hortaliças. Brasília: Embrapa Hortaliças. 49p.

COSTA FR; PEREIRA TNS; VITORIA AP; CAMPOS KP; RODRIGUES R.; DA SILVA DH; PEREIRA MG. 2006. Genetic diversity among Capsicum accessions using RAPD markers. Crop Breeding and Applied Biotechnology 6: 18-23.

DERERA NF. 2000. Condiment paprika: breeding, haversting \& commercialization. Kingston: RIRDC publication. 44p.

FRANCO J; CROSSA J; RIBOUT JM; BETRAN J; WARBURTON ML; KHAIRALLAH M. 2001. A method for combining molecular markers and phenotypic attributes for classifying plant genotypes. Theoretical and Applied Genetics 103: 944-952.

FRANCO J; CROSSA J; TABA S; SHANDS H. 2005. A sampling strategy for conserving genetic diversity when forming core subsets. Crop Science 45: 1035-1044.

GEPTS P. 2006. Plant genetic resources conservation and utilization: the accomplishments and future of a societal insurance policy. Crop Science 46: 2278-2296.

GONÇALVES LSA; RODRIGUES R; AMARAL JUNIOR AT; KARASAWA M; SUDRÉ CP. 2008. Comparison of multivariate statistical algorithms to cluster tomato heirloom accessions. Genetics and Molecular Research 7: 1289-1297.

GONÇALVES LSA; RODRIGUES R; AMARAL JUNIOR AT; KARASAWA M; SUDRÉ CP. 2009. Heirloom tomato gene bank: assessing genetic divergence based on morphological, agronomic and molecular data using a Ward-modified location model. Genetics and Molecular Research 8: 364-374.

GOWER JC. 1971. A general coefficient of similarity and some of its properties. Biometrics 27: 857-874.

INSTITUTO ADOLFO LUTZ. 1985. Normas analiticas do Instituto Adolfo Lutz: Métodos químicos e físicos para análise de alimentos. São Paulo: Instituto Adolfo Lutz. 533p.

IPGRI. 1995. Descriptores para Capsicum (Capsicum spp.). Roma: IPGRI. $51 \mathrm{p}$.

LANNES SD. 2005. Diversidade em Capsicum chinense: análise química, morfológica $e$ molecular. Viçosa: Editora UFV. 81p (Tese doutorado).

LANNES SD; FINGER FL; SCHUELTER AR; CASALI VWD. 2007. Growth and quality of Brazilian accessions of Capsicum chinense fruits. Scientia Horticulturae 112: 266-270.

LOTTI C; MARCOTRIGIANO AR; GIOVANNI C; RESTA P; RICCIARDI A; ZONNO V; FANIZZA G; RICCIARD L. 2008. Univariate 
and multivariate analysis performed on bio-agronomical traits of Cucumis melo $\mathrm{L}$. germplasm. Genetic Resources and Crop Evolution 55: 511-522.

MAECHLER M. 2007. Acessado em 16 de janeiro de 2008. The cluster package. Disponivel em http://www.r-project.org/.

MOHAMMADI SA; PRASANNA BM. 2003. Analysis of genetic diversity in crop plants - salient statistical tools and considerations. Crop Science 43: 1235-1248.

MOREIRA GR; CALIMAN FRB; SILVA DJH; RIBEIRO CSC. 2006. Espécies e variedades de pimentas. In: Informe Agropecuário. Belo Horizonte: Empresa de Pesquisa Agropecuária de Minas Gerais. p. 16-29.

MOSCONE EA; SCALDAFERRO MA; GRABIELE M; CECCHINI NM; GARCÍA YS; JARRET R; DAVIÑAJR; DUCASSE DA; BARBOZA GE; EHRENDORFER F. 2007. The evolution of chili peppers (Capsicum Solanaceae): a cytogenetic perspective. Acta Horticulturae 745: 137-169.

POZZOBON MT; SCHIFINO-WITTMAN; BIANCHETTI LB. 2006. Chromosome numbers in wild and semidomesticated
Brazilian Capsicum L. (Solanaceae) species: do $\mathrm{x}=12$ and $\mathrm{x}=13$ represent two evolutionary lines? Botanical Journal of the Linnean Society 151: 259-269.

RAMOS SRR. 2003. Divergência genética baseada em marcadores moleculares AFLP e indicação de coleção nuclear de Curcubita moschata para o nordeste do Brasil. Campos dos Goytacazes: UENF. 123p (Tese doutorado).

RODRÍGUEZ VM; CARTEA ME; PADILLA G; VELASCO P; ORDÁS A. 2005. The nabicol: a horticultural crop in northwestern Spain. Euphytica 142: 237-246.

SOKAL RR; ROHLF FJ. 1962. The comparison of dendrograms by objective methods. Taxon 11: 33-40.

SUDRÉ CP; CRUZ CD; RODRIGUES R; RIVA EM; AMARAL JUNIOR AT; SILVA DJH; PEREIRA TNS. 2006. Variáveis multicategóricas na determinação da divergência genética entre acessos de pimenta e pimentão. Horticultura Brasileira 24: 88-93.

SUDRÉ CP; LEONARDECZ E; RODRIGUES R; AMARAL JUNIOR AT; MOURA MCL;
GONÇALVES LSA. 2007a. Genetic resources of vegetable crops: a survey in the Brazilian germplasm collections pictured through papers published in the journals of the Brazilian Society for Horticultural Science. Horticultura Brasileira 25: 496-503.

SUDRÉ CP; LIMA MCC; PEREIRA TNS; COSTA GA; MOREIRA SO; COELHO KS; RODRIGUES R. 2007b. Germoplasma de pimenta: identificação de fontes de resistência à mancha bacteriana. In: CONGRESSO BRASILEIRO DE OLERICULTURA, 47. Resumos... Porto Seguro: SOB. p. 89.

SUDRÉ CP; GONÇALVES LSA; RODRIGUES R; AMARAL JUNIOR AT; RIVA-SOUZA EM; BENTO CS. 2010. Genetic variability in domesticated Capsicum spp as assessed by morphological and agronomic data in mixed statistical analysis. Genetics and Molecular Research 9: 283-294.

VIEIRAEA; CARVALHO FIF; BERTAN I; KOPP MM; ZIMMER PD; BENIN G; SILVA JAG; HARTWIG I; MALONE G; OLIVEIRA AC. 2007. Association between genetic distances in wheat (Triticum aestivum L.) as estimated by AFLP and morphological markers. Genetics and Molecular Biology 30: 392-399. 